\title{
Student Vehicle Identification Using Near Field Communication Technology
}

\author{
Nora Yanti Che Jan ${ }^{1 *}$, Mohd Nasharuddin Muhammad ${ }^{2}$ \\ ${ }^{1,2}$ Faculty of Computer and Mathematical Sciences, Universiti Teknologi MARA Perlis, Malaysia \\ Corresponding author: *yanticj@gmail.com \\ Received Date: 30 August 2018 \\ Accepted Date: 17 October 2018
}

\begin{abstract}
The purpose of this project is to develop a mobile application using NFC technology in order to assist security officers of Unit Keselamatan in UiTM Perlis branch. The main objective of the developed mobile application is to detect fake and stolen student vehicle stickers. Prior the development of the mobile application, security officers have no specific technique in detecting fake and stolen student vehicle stickers. Actions were only taken once complaints are received from the victims. NFC as defined by VasquezBriseno, Hirata et al. (2012) is a limited range high frequency wireless communication technology that allows the transfer of data among devices at distances lower than $10 \mathrm{~cm}$. NFC technology is a specialized subset within the family of RFID technology. The mobile application which is designed based on Automatic Identification Data Capture (AIDC) was later evaluated by ten security officers on its usability through questionnaire. Questions from the questionnaire are designed to evaluate several aspects including compatibility, content, navigation, interface design and general feedback. The results show that the officers are happy the developed mobile application as the application offers more than identifying stolen and fake vehicle stickers.
\end{abstract}

Keywords: NFC, RFID, mobile application, wireless communication technology

\section{INTRODUCTION}

Each student in UiTM Perlis Branch that wishes to bring his/her own vehicle is required to register the vehicle with Unit Keselamatan of UiTM Perlis Branch. Once the registration process is completed, the student will be issued with a sticker and this sticker must be displayed at the vehicle. Unlike staffs of UiTM Perlis Branch where their stickers are red in color, students' stickers are purple.

However, the issued plastic stickers do not have any latest security feature. Each sticker only has its serial number; printed on it and vehicle registration number which is written on its surface manually by the officers of Unit Keselamatan using marker pens. Besides the issue of faded handwritten vehicle registration number on the stickers over the time, stickers are always got stolen and forged by other unauthorized vehicles' owners. Unfortunately, the security officers cannot detect the stolen and forged stickers during rounds. This problem only comes to surface when the owner of the stolen or forged sticker lodges a report. As an alternative, this project is proposing to replace the current plastic-no-safety-feature sticker with a sticker that is equipped with Near Field Communication (NFC) tag.

As defined by Vazquez-Briseno et al. (2012), NFC is a limited range high frequency wireless communication technology that allows transfer of data among devices at distances lower than $10 \mathrm{~cm}$. This technology is an evolution from Radio Frequency Identification (RFID) technology and it was proposed and introduced by the NFC forum. In reality, NFC matched with RFID and mostly other technologies that are using a similar working platform. NFC produces the transmission speed of $106 \mathrm{Kbps}$ to $424 \mathrm{Kbps}$ in the 
communication frequency band of $13.56 \mathrm{MHz}$ similar with High Frequency RFID (Min Su, Dong Hwi, \& Kim, 2013). In addition to that, R. Steffen et al. (2010) stated that NFC offers three different operations modes; (1) active, (2) passive and (3) peer-to-peer communication. In active mode, devices such as Smartphones and other NFC devices are used to read and write tags. NFC tags are known as passive devices since they have no power of their own. A small amount of power will be taken by the NFC tags from the readers/writers to power the tags. For peer-to-peer communication, both devices need to be active.

The NFC tag introduced to Unit Keselamatan of UiTM Perlis Branch is capable of storing details about the owner of the vehicle, such as his/her name, course enrolled and contact number. Once the stickers are equipped with NFC tags, officers of Unit Keselamatan can easily use their own NFC-equipped smartphone to read data on the NFC tag during their rounds. These NFC-equipped smartphones are also required to be installed with the developed mobile application from this project. The developed mobile application is known as UiTMNFC. UiTMNFC offers more than just reading NFC tag. It also offers functions such as to write to the tag, to erase data from the tag as well as report where the officers can record some points as reference to assist them in writing reports, once they are back to the office after rounds.

NFC technology were chosen among the other AIDC techniques such as RFID and Quick Response Code (QR Code) due to the following reasons: (1) simplicity ; where transactions are run automatically, simply be touching a NFC reader, smartphone or an NFC tag (Madlmayr, Langer, Kantner, \& Scharinger, 2008), (2) higher security when compared to RFID and Bluetooth. According to Yaqub et al. (2012), due to the short range communication exist so fast that it becomes more difficult for hackers to hack the communication, and (3) safer data exchange since it is working through electromagnetic field induction, thus it is created for simple and safe data exchange directly among two devices (Steffen, Preißinger, Schöllermann, Müller, \& Schnabel, 2010).

There are two objectives to be achieved by this project: (1) to develop a mobile application using NFC technology to assist the officers of Unit Keselamatan in UiTM Perlis Branch in detecting stolen and forged vehicle stickers and (2) to evaluate the usability of the developed mobile application.

\section{CONSTRUCTION}

Two software are used in developing the mobile application; (1) Android Studio and (2) Adobe Photoshop CS6. Android Studio provides tools to build, test and debug the application, whereas Adobe Photoshop is used in create banners and logos as well as in pictures editing. All images created or edited in Adobe Photoshop are saved in .PNG format. Then, the images or pictures were imported to Android Studio. Figure 1 below shows an example of banner created for UiTMNFC. 


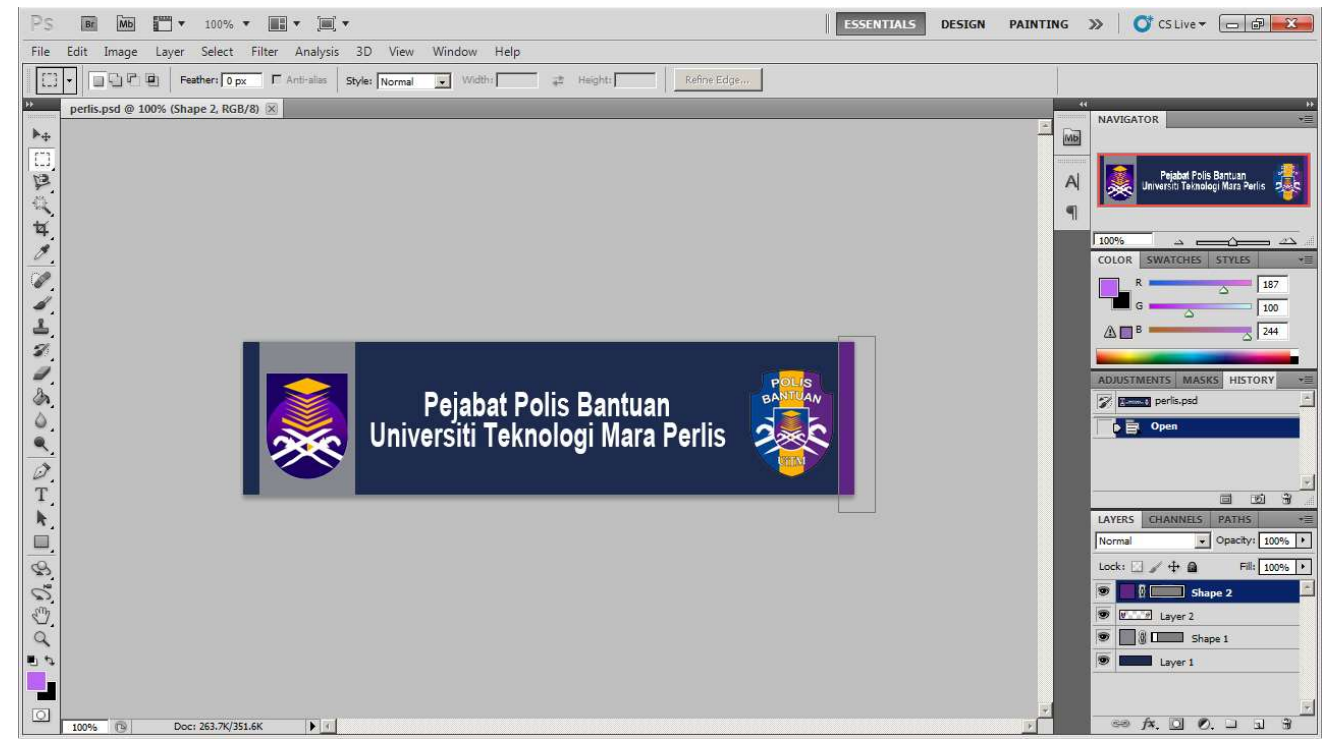

Figure 1: Banner of UiTMNFC

Development of UiTMNFC started with sketches of the interfaces on papers. Figure 2 and Figure 3 below are the early sketches for the UiTMNFC main homepage and its "Report" page respectively.

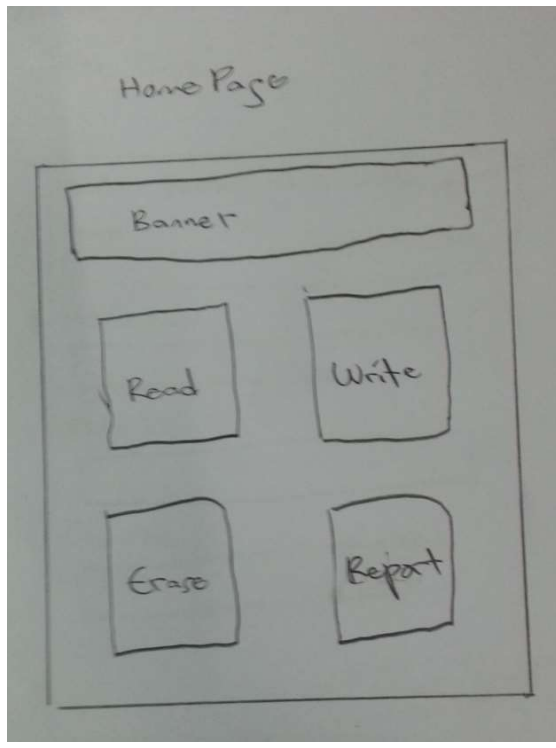

Figure 2: Sketch of the main homepage 


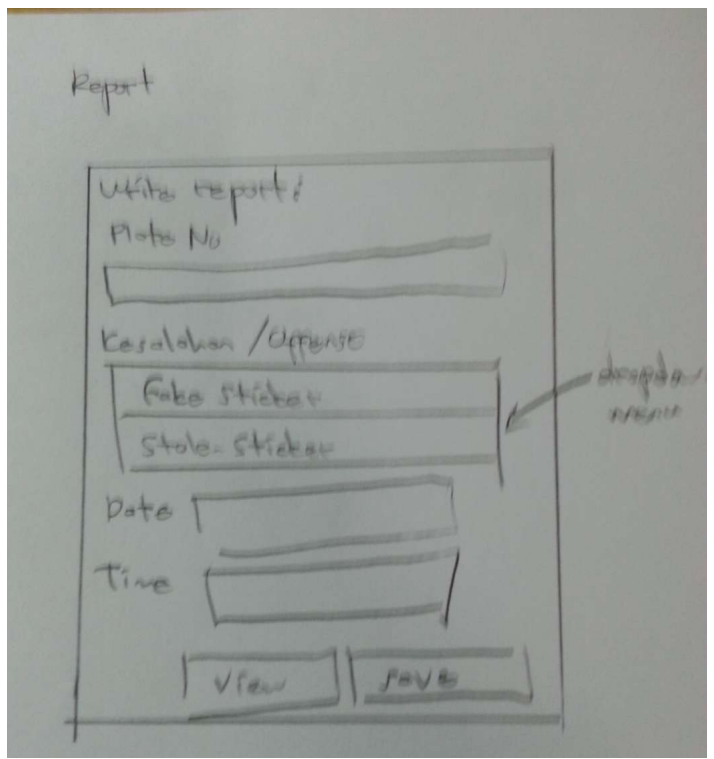

Figure 3: Sketch of the "Report" page

Below are some of the final interface designs of UiTMNFC. Figure 4 shows the homepage of the UiTMNFC. In the homepage, user is able to choose the operation he or she wishes to use. The options are Read, Write, Erase or Report.

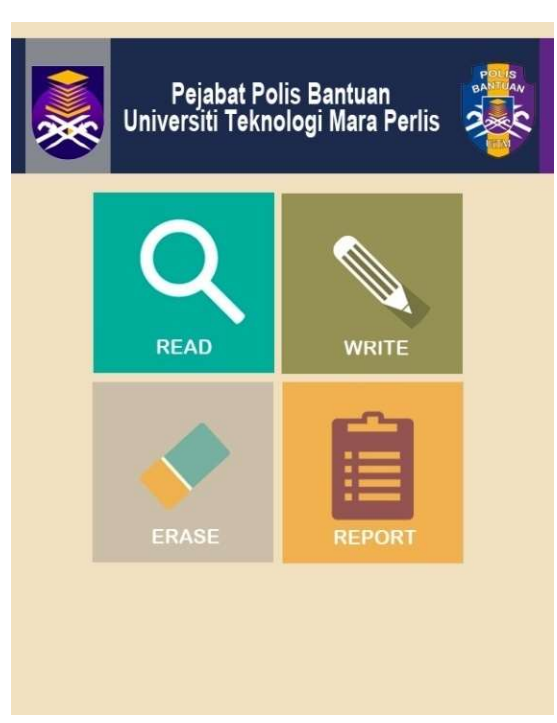

Figure 4: The homepage

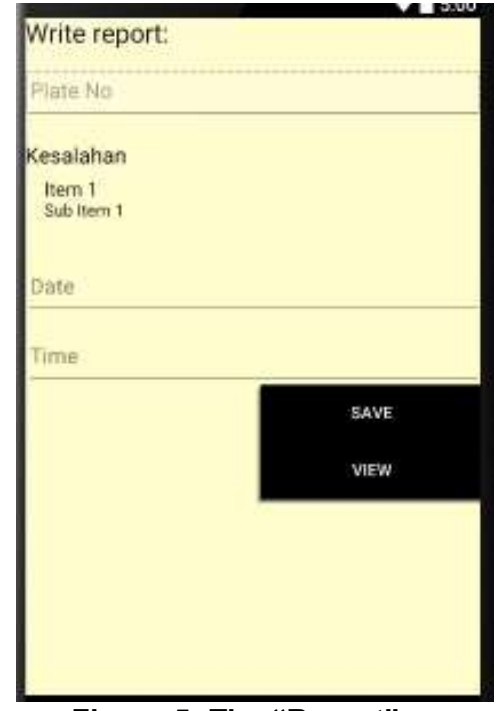

Figure 5: The "Report" page

Figure 5 is showing the interface of a page called "Report". This page allows the officers to jot down all the required details of the offences, so that later the officers may use the recorded details to write their reports after rounds.

In Figure 6 and 7 are the interfaces for "Reading" operation. Figure 6 shows the reading sticker interface when the users click on Read button displayed on the Homepage. After that, the user needs to tap 
the NFC sticker on back of his or her smartphone and the vehicle information such as name, matric number, registration number and contact number of the owner will appear as shown in Figure 7. The alert message "Sticker Detected" will appear when the user taps an NFC sticker. The toggle button has a function READ ON and READ OFF. If the user touches READ OFF, the information will not be displayed. The user can use back button on his or her smartphone to return to the Homepage.

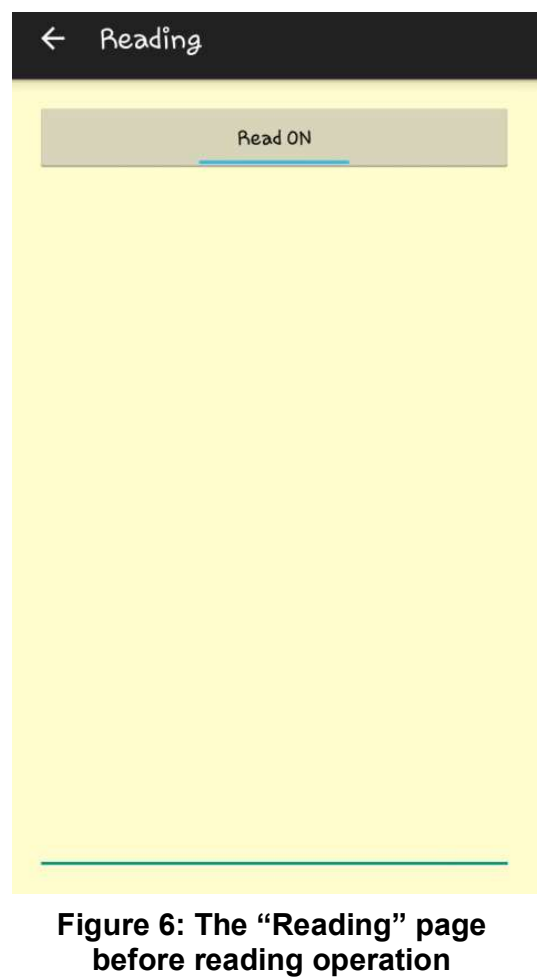

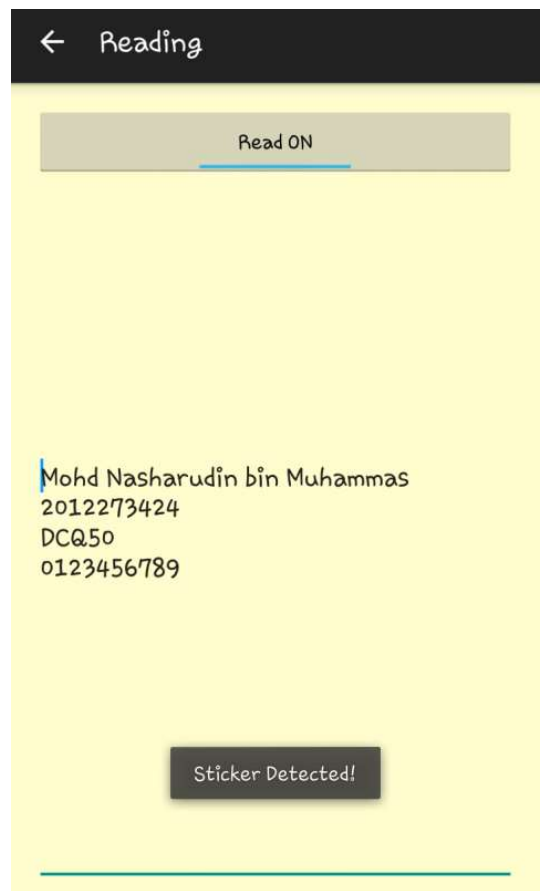

Figure 7: The "Reading" page once a sticker is detected

\section{FINDINGS AND DISCUSSION}

Once the mobile application is ready with all the features, usability testing is executed. Ten officers from the Unit Keselamatan of UiTM Perlis Branch were selected to answer all the questions listed in the questionnaires. These questionnaires were divided into five sections; (1) compatibility, (2) content, (3) navigation, (4) interface design and (5) generals feedbacks. Each section consists of a few numbers of questions and each question is answered with score ranging from 1 to 5 .

From the analysis done on Section 1 - Compatibility of the questionnaires that were distributed and collected, $80 \%$ of the respondents agreed that the application is compatible with most smartphones with built-in NFC capability and $80 \%$ of the respondents agreed that the layout of the developed application fits well with their smartphone screens. Section 2 - Content's scores however are not as good as scores in Section 1. For the process of writing, even though $90 \%$ of the respondents thought that the process of writing to the tags were easy, but almost all of the respondents thought that it will be easier if the process of writing to the tags were done through the desktop computers. When asked about the process of deleting the data stored on the tags, only $10 \%$ of the respondents chose "Neutral" as respond where as $90 \%$ of the respondent agreed that it is easy to delete data from the tags. The last feature of the application; Report did not received good scores from the respondents too. $70 \%$ of the respondents thought that the feature is not 
working perfectly as expected since they found difficulties in creating new reports and displaying the saved reports. There was even a suggestion that function Report should include small database to make data operation more efficient and faster. Section 3 - Navigation's score are doing well since almost $100 \%$ of the respondents found that all the menus and buttons provided are working and only $2.5 \%$ of the respondents stated that he/she did not understand the usage of the menu and buttons provided. In Section 4 - Interface Design, $100 \%$ of the respondents agreed that the interface was simple and interactive, and all the fonts, menus and buttons were displayed clearly on the screen. In the last section, which is Section 5 - General Feedback, $100 \%$ of the respondents are on the same page in stating that the application is user-friendly enough to use in performing the officers' daily tasks.

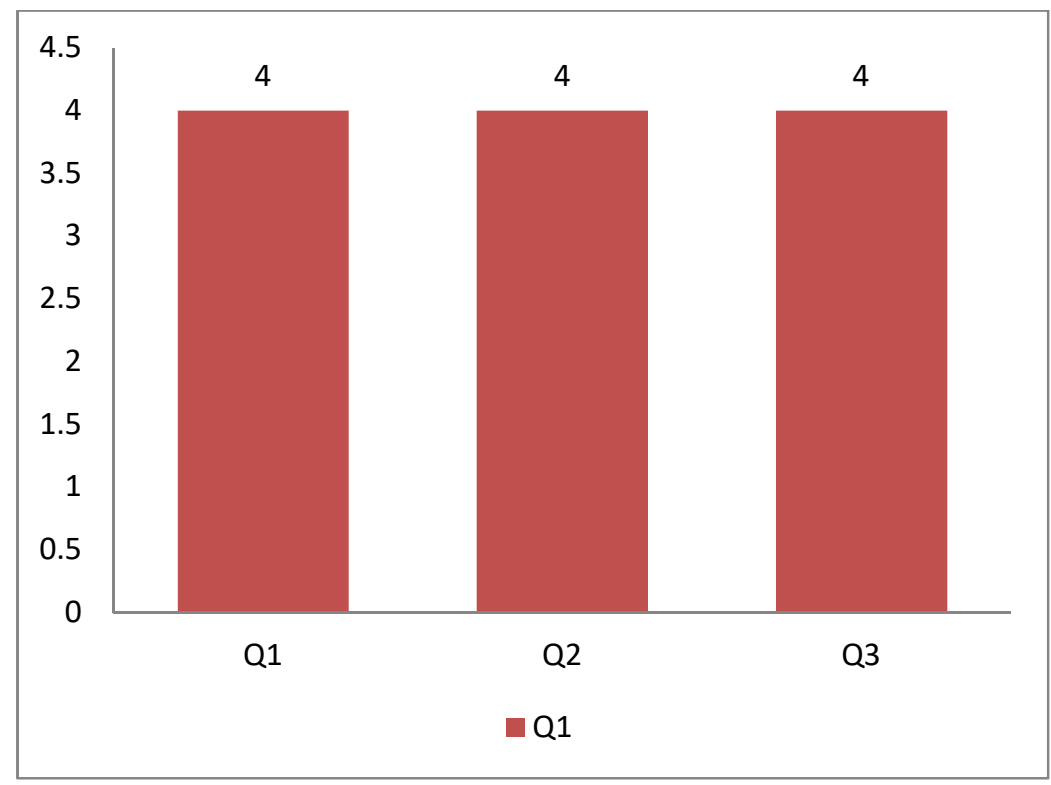

Figure 8: Results of Section 5

Figure 8 as shown above is the scores of Section 5 - General Feedback. All questions scored with the mean of 4. Question 1 is asking on the user-friendliness of the developed application, question 2 is asking whether the application is interesting or not and the last question is asking on the usefulness of the UiTMNFC.

\section{CONCLUSION AND RECOMMENDATION}

The developed mobile application; UiTMNFC has successfully assist the officers from Unit Keselamatan of UiTM Perlis Branch in detecting fake and stolen students' vehicle stickers. UiTMNFC also help the officers by providing all the necessary details in writing reports at the office after the rounds. However, there are several areas for improvement to the developed mobile application; (1) the application does not have a structured database like SQLite. Reports recorded by the officers are only saved on internal storage of the smartphone, in a text file format. This can cause an inconvenient when the officers want to view the recorded reports and (2) records written on NFC tag is currently stored in one type of NDEF record which is TextRecord, whereas NFC tag should be capable to storing multiple NDEF records. 


\section{REFERENCES}

Min Su, K., Dong Hwi, L., \& Kim, K. N. J. (2013, 24-26 June 2013). A Study on the NFC-Based Mobile Parking Management System. Paper presented at the Information Science and Applications (ICISA), 2013 International Conference.

Madlmayr, G., Langer, J., Kantner, C., \& Scharinger, J. (2008). NFC devices: Security and privacy. Paper presented at the Availability, Reliability and Security, 2008. ARES 08. Third International Conference.

Steffen, R., Prei, x00Df, inger, J., Scho, x, . . Schnabel, I. (2010, 20-20 April 2010). Near Field Communication (NFC) in an Automotive Environment. Paper presented at the Near Field Communication (NFC), 2010 Second International Workshop.

Steffen, R., Preißinger, J., Schöllermann, T., Müller, A., \& Schnabel, I. (2010). Near field communication (NFC) in an automotive environment. Paper presented at the International Workshop on Near Field Communication.

Vazquez-Briseno, M., Hirata, F. I., de Dios Sanchez-Lopez, J., Jimenez-Garcia, E., Navarro-Cota, C., \& Nieto-Hipolito, J. I. (2012). Using RFID/NFC and QR-Code in Mobile Phones to Link the Physical and the Digital World. Interactive Multimedia. Dr. Ioannis Deliyannis (Ed.) InTech, 219-242.

Yaqub, M. U., Shaikh, U. A., \& Mohandes, D. M. (2012). Near Field Communication, its application and implementation in KSA. 2012. 